\title{
"No espelho ponho a língua para fora": o corpo como a grande razão na poesia de Vera Casa Nova
}

\author{
Marcos Fabrício Lopes da Silva \\ Doutorando em Literatura Brasileira / UFMG
}

\begin{abstract}
RESUMO
Pretende-se neste artigo apresentar uma leitura crítica da poesia de Vera Casa Nova, presente no livro $1 q 1 k$ (1999), considerando a visão-de-mundo ali latente sobre o processo de autorreconhecimento do sujeito, que, diante do espelho, resolve, a partir de um exercício de compreensão existencial, interpretar as ações internas e externas ao seu corpo.
\end{abstract}

Palavras-Chave

Espelho, corpo, Vera Casa Nova

A representação literária do espelho enquanto objeto-personagem apresenta como uma de suas matrizes mais conhecidas a tradição oral, sendo um exemplo emblemático o conto de fadas “Branca de Neve e os sete anões”. Essa narrativa popular foi resgatada pelos Irmãos Grimm, que a registraram no livro Contos para a infância e para o lar, em 1812. Nessa narrativa, o espelho é responsável direto pela condução do enredo. Primeiramente, ele servirá como ilustre adereço, restringindo-se a sempre confirmar, em relação às demais mulheres, a beleza superior da rainha, quando consultado por ela. Mulher muito vaidosa, a rainha sempre perguntava ao espelho: “- Espelho, espelho meu, existe alguém mais bela do que eu?”1 Com o crescimento da graciosa Branca de Neve, o espelho modifica o seu parecer: “- Agora Branca de Neve é a mais bela.”2 A revelação deixa a rainha furiosa. Nesse caso, o espelho exerce sua autoridade oracular de forma despojada, ao fazer a distinção entre beleza e graça. Yves de La Taille, inspirado nos gregos, afirma que a beleza é estática, enquanto “a graça é,

\footnotetext{
${ }^{1}$ GRIMM; GRIMM. Branca de Neve e os sete anões, p. 4.

${ }^{2}$ GRIMM; GRIMM. Branca de Neve e os sete anões, p. 5.
} 
justamente, a beleza em movimento”. ${ }^{3}$ Aplicado ao contexto do conto de fadas em questão, constata-se, pela nova avaliação do espelho, que a beleza encontra-se estaticamente na rainha e dinamicamente na Branca de Neve. Nessa personagem, a exterioridade graciosa seria um desdobramento natural da interioridade. Tanto é que a linda princesa não precisava consultar o espelho, para depender do aval dele, quanto a reconhecê-la como bela, diferentemente do comportamento da rainha. Como manifestação da interioridade, a beleza exterior de Branca Neve evidencia a autoestima da personagem, que experimenta "uma sensação íntima de bemestar". ${ }^{4}$ Por sua vez, beleza a reboque somente da exterioridade concentra-se exclusivamente na vaidade, de acordo com Flávio Gikovate, ${ }^{5}$ sendo esta perseguida a todo custo, narcisicamente, pela malvada rainha.

Na ficção brasileira, a autoestima ganhou como representação literária a nomeação machadiana de “alma interior”. Esta, centrada no Eu particular, é responsável pelo olhar individualizado, que parte "de dentro para fora”. ${ }^{6}$ Ainda no fabuloso conto "O espelho: esboço de uma nova teoria de alma humana” (1882), Machado de Assis apresenta a vaidade como sendo a manifestação da "alma exterior”, constituída pelo Outro que "olha de fora para dentro", 7 avaliando, assim, as atitudes do indivíduo.

É possível relacionar os conceitos de “alma exterior” e "alma interior” às noções de aparência e essência, forma e conteúdo, máscara e rosto, vaidade e autoestima, respectivamente. Quando o protagonista do conto machadiano, Jacobina, deixa de ser um humilde morador do interior para se tornar alferes da Guarda Nacional, a força do papel social decorrente da patente é tamanha que implicará na mudança de nome do personagem. No contato com os que o cercam, aos poucos o cargo começa a se sobrepor ao homem: "E sempre alferes; era alferes para cá, alferes para lá, alferes a toda hora. Eu pedia-lhe que me chamasse Joãozinho, como dantes; e ela [tia Marcolina] abanava a cabeça, bradando que não, que era o 'senhor alferes',„8

A ironia machadiana, no conto, atinge um dos seus ápices na cena em que Jacobina, solitário, posa fardado horas e horas diante de um espelho. No início, o contato com aquele objeto decorativo foi traumatizante, pois Jacobina, sem a farda, não passava de uma figura

\footnotetext{
${ }^{3}$ CORTELLA; LA TAILLE. Nos labirintos da moral, p. 62.

${ }^{4}$ GIKOVATE. Auto-estima não é vaidade, p. 208.

${ }^{5}$ GIKOVATE. Auto-estima não é vaidade.

${ }^{6}$ MACHADO DE ASSIS. O espelho: esboço de uma nova teoria da alma humana, p. 346.

${ }^{7}$ MACHADO DE ASSIS. O espelho: esboço de uma nova teoria da alma humana, p. 346.

${ }^{8}$ MACHADO DE ASSIS. O espelho: esboço de uma nova teoria da alma humana, p. 347.
} 
“vaga, esfumaçada, difusa, sombra de sombra”. ${ }^{9}$ Após ter se lembrado da vestimenta, ele se volta para o espelho e o resultado passa ser outro:

O vidro reproduziu então a figura integral; nenhuma linha de menos, nenhum contorno diverso; era eu mesmo, o alferes que achava, enfim, a alma exterior. Essa alma ausente com a dona do sítio, dispersa e fugida com os escravos, ei-la recolhida no espelho. ${ }^{10}$

Sem a farda, Jacobina era obrigado a voltar as suas origens, o que lembrava a sua antiga forma de identificação - Joãozinho. Tal postura fazia recordá-lo tragicamente da vida pacata e do anonimato, provenientes da condição provinciana. Como Jacobina só se reconhecia como alferes, a necessidade de ficar preso à farda se justificava. A imagem que existia antes se perde, aliena-se em favor da que surge, repleta de satisfações narcísicas. A alma exterior era a consciência, na verdade a personificação da crítica; elogio dos pais e depois da sociedade: Joãozinho apaga-se perante o alferes, que todos ajudaram a construir. O fulcro de sua personalidade não se encontrava em sua interioridade, mas na sua farda de alferes, sem a qual sequer sua imagem no espelho era nítida.

Além do ilustre exemplo machadiano, temos uma série literária brasileira de qualidade diferenciada no tratamento dado à temática do espelhamento. Em Primeiras estórias (1962), mais especificamente no conto “O espelho”, Guimarães Rosa constrói um narrador que, na tentativa de encontrar a sua verdadeira essência, aplica em si um método cujo propósito era o de experimentar as diferentes formas que poderiam brotar de sua própria imagem no espelho até chegar ao ponto de não se conseguir ver nenhuma imagem. O personagem resolve paralisar as experiências e não dirigir mais o olhar a espelho algum. Porém, num certo dia, ao se deparar com o objeto novamente, um quase rosto se revela. O narrador se sente contente e tranquilo com tal imagem, o que o leva a convidar o leitor a refletir sobre o que é de fato a vida, para além da mentira que é a aparência humana. Nesse processo de nudez existencial frente ao espelho considerado instrumento de análise, o narrador, ao longo de suas experiências, vai descartando seus reflexos um a um até emergir a seguinte imagem, “o eu por trás de mim”, traduzido por "um rostinho de menino, de menos-que-menino”. Eis a ideia de que a criança enxerga melhor a verdade. Tornando-se adulto, a visão de si se torna cada vez mais embaçada, pois, ao longo da constituição da imagem do personagem refletida no espelho, a autenticidade identitária se dilui para entrar em cena a projeção de seus pais, de suas paixões, das ideias que os outros lhe atribuem, dos interesses efêmeros.

\footnotetext{
${ }^{9}$ MACHADO DE ASSIS. O espelho: esboço de uma nova teoria da alma humana, p. 350.

${ }^{10}$ MACHADO DE ASSIS. O espelho: esboço de uma nova teoria da alma humana, p. 352.
} 
Outra linha de autores que se motivaram a escrever sobre a tomada de consciência do sujeito projetada no espelho é formada por poetas como Cecília Meireles, Conceição Evaristo, Martha Medeiros e Vera Casa Nova. Em relação às duas primeiras autoras, os poemas “Retrato” (1939), de Cecília Meireles, e “Da mulher, o tempo...” (2008), de Conceição Evaristo, são exemplos literários de como as reflexões existenciais realizadas pelo eu poético passam pelas mudanças sentidas no próprio corpo, sendo estas visivelmente evidenciadas e processadas no contato com o espelho. Era como se nesses textos, em vez de o sujeito perguntar, a partir de uma motivação vaidosa, como fez a madrasta de Branca Neve “espelho, espelho meu, existe alguém mais bela do que eu?" ${ }^{11}$-, optasse conscientemente por um questionamento interior e dinâmico, a exemplo daquele feito pela poeta Martha Medeiros, em Strip-tease: “espelho, espelho meu / existe no mundo alguém / que reflita mais do que eu?."12

Em relação à poesia de Vera Casa Nova, sobre a qual vamos nos debruçar mais detidamente, o tema da corporeidade ganha relevância, na medida em que o eu-poético exterioriza de maneira radical o seu repertório epistemológico comprometido com o estarpresente no mundo. Em $1 k 1 q$, de 1999, a poeta carioca e professora da Faculdade de Letras da UFMG compôs o seguinte quadro literário de espelhamento, norteado pela abordagem do corpo como linguagem subjetiva do exercício da maturidade necessária para a expressão plenamente ousada da condição humana:

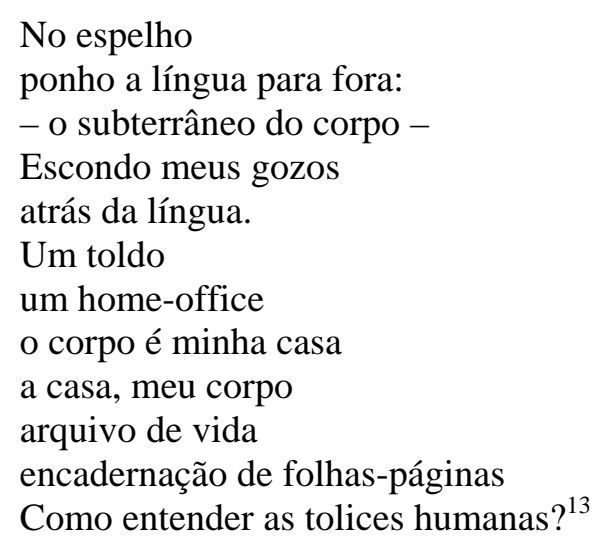

O ato de se despir diante do espelho até atingir o "subterrâneo do corpo" tem como rito de iniciação a proposta abusada e destemida de expor a língua para fora, fazendo com que o eu-lírico manifeste sua verdade íntima encontrada na corporalidade expressiva. Qual a

\footnotetext{
${ }^{11}$ GRIMM; GRIMM. Branca de Neve e os sete anões, p. 4.

${ }^{12}$ MEDEIROS. Strip-tease (1985), p. 67.

${ }^{13}$ CASA NOVA. $1 q 1 k$, p. 12.
} 
relação entre o espelho e a identidade corpórea do sujeito ali espelhado? No caso do texto de Casa Nova, o espelho ocupará o espaço de mediador. A palavra “espelho” origina-se do latim speculum, que também formou o verbo “especular”. Especular é pensar, refletir. O pensamento é o mediador essencial. Conforme salienta Manuel Antônio de Castro, ${ }^{14}$ de um lado, a especulação se remete para o conhecimento e, de outro, para a representação, pois o espelho é aquele que forma a imagem na qual o sujeito se vê como tal. Só que o espelho não oferece o que o indivíduo é, mas a imagem dele, ou seja, sua representação. Casa Nova, ao escolher o espelho para refletir sobre a identidade humana, aponta que tal objeto serve como reflexo, portanto, representação, mas é a pessoa refletida nele que protagoniza a reflexão, o conhecimento, ao estar ali às voltas com seu interior e subjetividade.

Repare que nem tudo esta às claras na exposição identitária relatada no poema: “escondo meus gozos atrás da língua”. Trata-se de uma atitude elogiosa que celebra o doce mistério da intimidade, além de haver naquela passagem um indicativo de oposição ao excesso de luz que limita a compreensão da essência ao enquadramento coercitivo da aparência, das conveniências sociais. É no exercício da interioridade, no campo privado, que experimentamos a medida e o significado do nosso corpo e da nossa pessoa. Estar consigo próprio significa, nesse sentido, alcançar um ponto interno em que somos nós mesmos mais completamente, o que nos permite assumir nossos potenciais criativos para o amor e para o trabalho, sermos mais lúcidos e mais saudáveis, e, assim, compreendermos e nos relacionarmos com o mundo e com as outras pessoas. Antes de se tornar prazer compartilhado, o gozo, no poema, se desenha como autoapreço, amor-próprio, cujo ponto de partida existencial não é o verbo que nos projeta externamente, mas o silêncio que nos acompanha internamente. “Atrás da língua” se mostra como o locus emblemático no qual se realiza o conhecimento de si mesmo, ou seja, a consciência da própria presença, entendida como sinônimo de corporificação. Se, biblicamente, a língua foi considerada como chicote do corpo, considerando o mau emprego comunicativo conferido a ela pela Humanidade, na poesia de Casa Nova, o mencionado órgão do corpo humano representa a libertação do corpo. É pela língua que o eu-poético pode apreciar os sabores e dissabores provenientes da experiência vital, ou seja, sentir os variados gostos da existência. Nesse sentido, o corpo é convocado pelo eu-poético como se fosse o "centro do mundo do Ser”, ${ }^{15}$ ou seja, referência de construção do autorreconhecimento.

\footnotetext{
${ }^{14}$ CASTRO. Tempos de metamorfose.

${ }^{15}$ MONTEIRO. Quem somos nós?: o enigma do corpo.
} 
Saber quem somos, conforme pretende o eu-poético elaborado por Casa Nova, significa sermos transparentes com nós mesmos. Se o corpo é o enigma, a chave para desvendá-lo deve estar nele próprio. Infere-se na leitura do citado poema que não convém acionar o espelho para se obter respostas íntimas, visto que estas se encontram no interior do próprio sujeito. “Conheça-te a ti mesmo”, já ressaltava, desde os tempos gregos, a inscrição presente no Óraculo de Delfos.

O efeito carnavalizador do poema se faz presente na abordagem invertida proposta pela poeta: é o subsolo identitário que ocupa o centro das atenções, enquanto o playground camaleônico da personalidade é desmascarado pela vontade sincera e honesta presente no eupoético ambicionado em revelar visceralmente ao espelho tanto as suas dores como os seus prazeres. É nessa encruzilhada da existência que o corpo, parodiando Pascal, tem razões que a própria razão desconhece. Em Assim Falou Zaratustra (1883-1885), o filósofo Nietzsche, ao batizar o corpo com o nome de Grande Razão, por oposição àquela razão pequena e acessória que parece residir dentro da caixa craniana, nos oferece luz de compreensão a respeito da sabedoria visceral perseguida pelo eu-poético concebido por Casa Nova. Nesse sentido, é emblemática a seguinte passagem do poema: “o corpo é minha casa / a casa, meu corpo / arquivo de vida / encadernação de folhas-páginas.”16 As dobras de um corpo dizem muito, porque a vida guarda nos sulcos da pele os segredos do tempo. Entre a memória e o esquecimento, estão encadernadas as lembranças e os traumas que compõem o livro da vida. Diferentemente do "corpo-máquina”, ${ }^{17}$ fundamentado apenas para executar, para fazer sem refletir, vestindo-se de roupagens que executam normas, buscando a estabilidade, o chão, a certeza e a ordem, o eu-poético de Vera Casa Nova se mostra diferente, “corpo vivo”. ${ }^{18}$ Filho do desvio e da incerteza, ele sabe que seu desígnio é mudar diante das "batidas na porta da frente”, desferidas pelo tempo. O corpo vivo, como morada existencial, é autêntico na ação, autônomo na composição.

No ritual de espelhamento destacado pela poeta, o reflexo trazido pelo espelho é interpretado pelo sujeito que nele se reflete, a partir de uma reflexão identitária que se dá pela relevância que o próprio indivíduo confere à projeção afetiva e sensível de seus impulsos e anseios. Menosprezado pela valorização do mundo inteligível em detrimento do mundo sensível, aspecto que marca a tradição metafísica ocidental, o corpo, para além da querela

\footnotetext{
${ }^{16}$ CASA NOVA. $1 q 1 k$, p. 12.

${ }^{17}$ MONTEIRO. Quem somos nós?: o enigma do corpo, p. 55.

${ }^{18}$ MONTEIRO. Quem somos nós?: o enigma do corpo, p. 56.
} 
dualista nas relações entre matéria e espírito, é ressignificado positivamente por Vera Casa Nova e Nietzsche. Como protagonista epistemológico da vida, o corpo, nos autores em questão, é reconhecido em seu lugar de destaque na história do pensamento, pois é nele que testemunhamos os inexoráveis traços, vestígios e marcas do tempo, nos quais se evidenciam os prazeres e desprazeres decorrentes da experiência vital.

Face ao exposto, vale a pena reproduzir o pensamento de valorização do corpo do filósofo alemão: “o corpo é uma razão em ponto grande, uma multiplicidade com um só sentido, uma guerra e uma paz, um rebanho e um pastor."19 Para compreender o corpo como Grande Razão, o indivíduo precisa ultrapassar seus posicionamentos vaidosos para mergulhar em si em busca de seus juízos de valor mais aprofundados sobre a existência intra e interpessoal: “tu dizes ‘eu’ e orgulhas-te dessa palavra. No entanto, maior - coisa que tu não queres crer - é o teu corpo e a tua razão grande. Ele não diz Eu, mas: procede como Eu.”20 Autoconsciente é o indivíduo que consegue fazer a leitura do seu próprio corpo para compreendê-lo nos seus pressupostos explícitos e implícitos, que se tornam evidentes nas experiências de dor e de alegria: "há mais razão no teu corpo do que na tua melhor sabedoria.”21 Nesse sentido, o corpo não é um mero objeto, nem uma simples ideia. Ele é movimento, sensibilidade e expressão criadora. É o que podemos perceber no comportamento do eu-poético desenvolvido por Casa Nova, que se alimenta do motor corporal como "energia em ação" 22 para melhor digerir as ocorrências da vida. Dessa forma, essência e existência apresentam-se como dimensões de um mesmo fenômeno: o ser humano. Percepção e pensamento mostram-se indissociáveis no fazer reflexivo-performático presente no poema em tela. Neste, parte-se da premissa de que a corporeidade se constrói na manifestação relacional do homem consigo e com o universo. Longe de ser "matéria sólida, sem movimento", ${ }^{23}$ o corpo humano é assim compreendido como um processo, uma organização em constante alteração e transformação, um movimento que precisa ser acompanhado de dentro e não comandado de fora.

Pôr a língua para fora, a exemplo do que foi feito na poesia de Vera Casa Nova, é expor abertamente o que a boca guarda e a comunicação do interior humano revela. Temos, nesse autoexame inventivo, um eu-poético que ultrapassa a dicotomia cronológica entre o

\footnotetext{
${ }^{19}$ NIETZSCHE. Assim falou Zaratustra, p. 41.

${ }^{20}$ NIETZSCHE. Assim falou Zaratustra, p. 41.

${ }^{21}$ NIETZSCHE. Assim falou Zaratustra, p. 41.

${ }^{22}$ MONTEIRO. Quem somos nós?: o enigma do corpo, p. 14.

${ }^{23}$ MONTEIRO. Quem somos nós?: o enigma do corpo, p. 14.
} 
novo e o velho para aprofundar-se no tempo psicológico. Ele, assim, experimenta no próprio corpo, sustento de sua razão vital, o autorreconhecimento trazido à baila enquanto "arquivo vivo”. Experimentando em si a condição de metamorfose ambulante, esse sujeito poético se percebe como fruto de sucessivas edições existenciais à disposição do cont(r)ato de leitura com o Outro, a partir da autêntica exposição face to face com o espelho, protagonizando, por assim dizer, reflexos imbuídos de reflexões. Estas, por sua vez, se apresentam por meio de uma travessia identitária construída tanto pela percepção aprofundada de um "universo particular” como pela indagação ética proveniente do esforço de se compreender os caminhos tortuosos da existência humana.

\begin{abstract}
This article makes a critical reading of Vera Casa Nova's poetry in the book $1 q 1 k$ (1999), considering the point of view of the imaging process of selfrecognition of the subject who, in front of the mirror, decides from an exercise of existential comprehension to interpret the internal and external actions of her body.
\end{abstract}

KEYWORDS

Mirror, body, Vera Casa Nova

\title{
REFERÊNCIAS
}

CASA NOVA, Vera. 1q1k. Belo Horizonte: Edições 2 Luas, 1999. p. 12.

CASTRO, Manuel Antônio de. Tempos de metamorfose. Rio de Janeiro: Tempo Brasileiro, 1994. 218 p.

CORTELLA, Mario Sergio; LA TAILLE, Yves de. Nos labirintos da moral. 5. ed. Campinas, SP: Papirus 7 Mares, 2009. 112 p.

EVARISTO, Conceição. Da mulher, o Tempo... . In: Poemas da recordação e outros movimentos. Belo Horizonte: Nandyala, 2008. p. 26-27.

GIKOVATE, Flávio. Auto-estima não é vaidade. Cláudia, São Paulo, p. 208, jul. 1996.

GRIMM, Jacob; GRIMM, Wilhelm. Branca de Neve e os sete anões. São Paulo: Melhoramentos, 1982. 15p.

GUIMARÃES ROSA. Primeiras estórias. Rio de Janeiro: Nova Fronteira, 2005. 
MACHADO DE ASSIS. O espelho: esboço de uma nova teoria da alma humana. In: Papéis avulsos (1882). In: COUTINHO, Afrânio (Org.). Obra completa. Rio de Janeiro: Nova Aguilar, 1997. v. 2. p. 345-352.

MEDEIROS, Martha. Strip-tease (1985). In: . Poesia reunida. Porto Alegre: L\&PM, 1999.

MEIRELES, Cecília. Poesias completas. Rio de Janeiro: Civilização Brasileira, 1973-76.

MONTEIRO, Pedro Paulo. Quem somos nós?: o enigma do corpo. Belo Horizonte: Gutenberg, 2004. 172 p.

NIETZSCHE, Friedrich. Assim falou Zaratustra. São Paulo: Martin Claret, 2003. 243 p. 